\title{
Influence of Hot Implantation on Residual Radiation Damage in Silicon Carbide
}

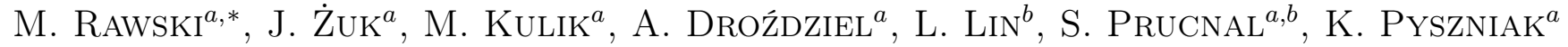 \\ AND M. TUREK ${ }^{a}$ \\ ${ }^{a}$ Institute of Physics, Maria Curie-Skłodowska University, Pl. M.C. Skłodowskiej 1, 20-031 Lublin, Poland \\ ${ }^{b}$ Institute of Ion Beam Physics and Materials Research, Helmholtz-Zentrum Dresden-Rossendorf \\ P.O. Box 510119, 01314 Dresden, Germany
}

\begin{abstract}
Remarkable thermomechanical and electrical properties of silicon carbide $(\mathrm{SiC})$ make this material very attractive for high-temperature, high-power, and high-frequency applications. Because of very low values of diffusion coefficient of most impurities in $\mathrm{SiC}$, ion implantation is the best method to selectively introduce dopants over well-defined depths in SiC. Aluminium is commonly used for creating $p$-type regions in SiC. However, post-implantation radiation damage, which strongly deteriorates required electric properties of the implanted layers, is difficult to anneal even at high temperatures because of remaining residual damage. Therefore implantation at elevated target temperatures (hot implantation) is nowadays an accepted method to decrease the level of the residual radiation damage by avoiding ion beam-induced amorphization. The main objective of this study is to compare the results of the Rutherford backscattering spectroscopy with channeling and micro-Raman spectroscopy investigations of room temperature and $500{ }^{\circ} \mathrm{C} \mathrm{Al}^{+}$ion implantation-induced damage in $6 \mathrm{H}-\mathrm{SiC}$ and its removal by high temperature (up to $1600{ }^{\circ} \mathrm{C}$ ) thermal annealing.
\end{abstract}

PACS: 61.72.U-, 78.30.-j, 61.05.Np, 63.50.-x, 79.20.Rf, 81.70.Fy

\section{Introduction}

Silicon carbide, because of its excellent thermomechanical and electrical properties has attracted a great attention of many researchers [1-3]. SiC is a very promising material for high-temperature, high-frequency and high-power electronic devices. However, manufacturers of such devices encounter many technical problems which originate in specific physical properties of $\mathrm{SiC}[4,5]$. Those properties are, among others, the following: very low dopant diffusion coefficients, high susceptibility to amorphization during ion-irradiation and relatively high sublimation temperature.

High fluence $\mathrm{Al}^{+}$ion implantation is the most promising procedure to fabricate low resistivity $p$-type regions in $\mathrm{SiC}[3,6]$. However, radiation damage consisting of vacancies, interstitials and extended defects is the undesired effect of ion implantation, which at high ion fluences can even lead to amorphization of subsurface SiC layers of a few hundred nanometers thickness. This work is focused on crystalline quality improvement of the $\mathrm{Al}^{+}$ion implanted $6 \mathrm{H}-\mathrm{SiC}$ by performing ion implantation into targets at elevated temperatures (hot implantation) to hinder amorphization process. As a result, after post-

\footnotetext{
* corresponding author; e-mail: michal.rawski@gmail.com
}

-implantation annealing at $1500-1600{ }^{\circ} \mathrm{C}$ the quality of the hot-implanted layers is expected to be higher than following implantations at room temperature (RT), and in some cases the lattice recovery is almost complete.

One of the well-established methods of radiation damage investigation in semiconductors is the Rutherford backscattering spectrometry with channeling (RBS/C). Although very useful, the technique is destructive, time-consuming and needs expensive equipment to accelerate protons or alpha particles in the $\mathrm{MeV}$ energy range. The Raman scattering is a fast, relatively cheap and non-destructive method for the investigation of phonons in solids. More specifically, the technique can be used for investigation of residual damage in ion-implanted materials. The present work is aimed at comparison of the information obtained from RBS/C and micro-Raman investigations of $\mathrm{Al}^{+}$ion-implanted and annealed $\mathrm{SiC}$.

\section{Experiment}

Single crystals of silicon carbide ( $6 \mathrm{H}$ polytype) were grown in the Institute of Electronics Materials Technology (ITME) in Warsaw. Polished 6H-SiC platelets were implanted with the UNIMAS 79 ion implanter (Maria Curie-Skłodowska University) using $\mathrm{Al}^{+}$ion beam at the angle $10^{\circ}$ from [0001] $6 \mathrm{H}-\mathrm{SiC}$ to avoid channeling. We used an arc discharge ion source of our construction to produce $\mathrm{Al}^{+}$ions [7-9]. The ion beam current 
density at the target was kept below $1.0 \mu \mathrm{A} / \mathrm{cm}^{2}$. Implantation process was simulated with the SRIM 2008 computer code [10]. To obtain a quasi-rectangular shape of Al concentration depth profiles, sequential implantations were performed starting from the highest ion energy $(220 \mathrm{keV})$ to the lowest $(90 \mathrm{keV})$. For hot implantation at target temperature of $500{ }^{\circ} \mathrm{C}$ a specially designed hot stage with a Boraelectric (Tectra) HTR 1002 heater was used. Total ion fluence was $9 \times 10^{14} \mathrm{~cm}^{-2}$ (Table I). After the implantation process $6 \mathrm{H}-\mathrm{SiC}$ samples were annealed at 1300,1500 or $1600^{\circ} \mathrm{C}$ for $10 \mathrm{~min}$ in $\mathrm{Ar}$ atmosphere at a pressure of $100 \mathrm{~Pa}$.

\section{TABLE I}

Sequential implantation parameters.

\begin{tabular}{c|c}
\hline \hline Ion energy [keV] & Fluence [ion $\left./ \mathrm{cm}^{2}\right]$ \\
\hline 220 & $5.15 \times 10^{14}$ \\
165 & $1.02 \times 10^{14}$ \\
130 & $1.64 \times 10^{14}$ \\
90 & $1.16 \times 10^{14}$
\end{tabular}

The analysis of implanted $6 \mathrm{H}-\mathrm{SiC}$ layers was performed by the RBS/C at the Rossendorf Institute [11]. We used a $1.7 \mathrm{MeV} \mathrm{He}{ }^{+}$ion beam of $1 \mathrm{~mm}$ diameter. Energy spectra of ions backscattered from the [0001] oriented $6 \mathrm{H}-\mathrm{SiC}$ samples were measured at an angle of $170^{\circ}$ at RT.

The Raman scattering investigations of implanted samples were performed at RT with a Renishaw inVia micro-Raman spectrometer in backscattering geometry. The excitation light was provided by the $514.5 \mathrm{~nm}$ wavelength argon ion laser beam of a $1 \mu \mathrm{m}$ focus diameter. All the spectra were taken at the incident beam power of $10 \mathrm{~mW}$ and using the same slits width of the Raman microscope. Both the excitation and collection of the scattered light were performed using a confocal system with a $100 \times$ Raman microscope objective. Time of data acquisition of each spectrum was $10 \mathrm{~s}$ with 6 accumulations.

\section{Results and discussion}

\section{1. $R B S / C$ investigations}

The results of the $\mathrm{RBS} / \mathrm{C}$ measurements are displayed in Figs. 1-3. 6H-SiC samples were subjected to $\mathrm{Al}^{+}$ion implantation at RT, followed by high temperature annealing at 1300,1500 or $1600{ }^{\circ} \mathrm{C}$. Substantial dechanneling of the analyzing ions without any damage peaks is observed in the $\mathrm{RBS} / \mathrm{C}$ spectra when compared to aligned spectrum taken on unimplanted (virgin) $6 \mathrm{H}-\mathrm{SiC}$ (Fig. 1). After annealing at $1300^{\circ} \mathrm{C}$ the level of residual radiation damage in samples implanted at RT is much higher than in hot-implanted $\left(500^{\circ} \mathrm{C}\right) 6 \mathrm{H}-\mathrm{SiC}$. The annealing at $1500^{\circ} \mathrm{C}$ of the hot-implanted samples results in a remarkable reconstruction of crystalline order, whereas $6 \mathrm{H}-\mathrm{SiC}$ implanted at RT does not show such properties

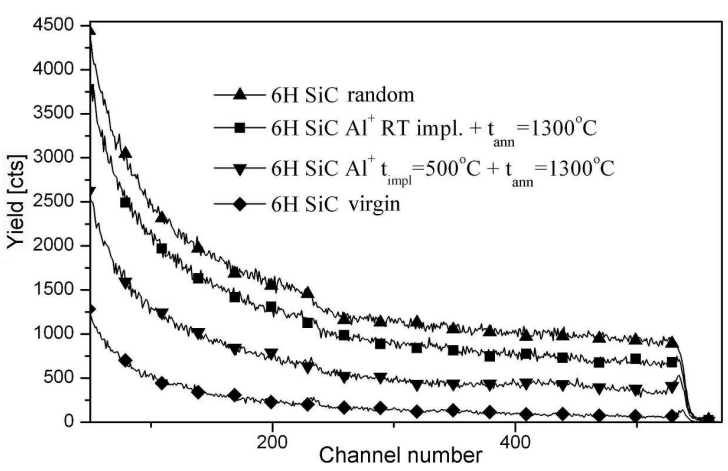

Fig. 1. RBS/C spectra of $\mathrm{Al}^{+}$implanted and $1300{ }^{\circ} \mathrm{C}$ annealed $6 \mathrm{H}-\mathrm{SiC}$ samples. Additionally, aligned and random spectra of a virgin sample are shown.

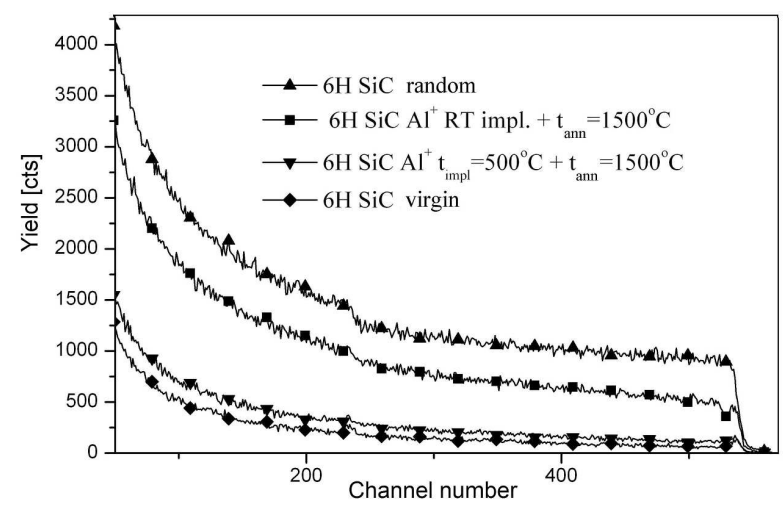

Fig. 2. RBS $/ \mathrm{C}$ spectra of $\mathrm{Al}^{+}$implanted and $1500^{\circ} \mathrm{C}$ annealed $6 \mathrm{H}-\mathrm{SiC}$ samples. Additionally, aligned and random spectra of unimplanted $6 \mathrm{H}-\mathrm{SiC}$ are shown.

(Fig. 2). When annealing at $1600{ }^{\circ} \mathrm{C}$ was applied, the hot-implanted samples recovered nearly to the perfect crystal quality of virgin $6 \mathrm{H}-\mathrm{SiC}$ (Fig. 3). It is also shown in the same figure that the yield corresponding to the non-annealed, RT implanted sample reaches the random

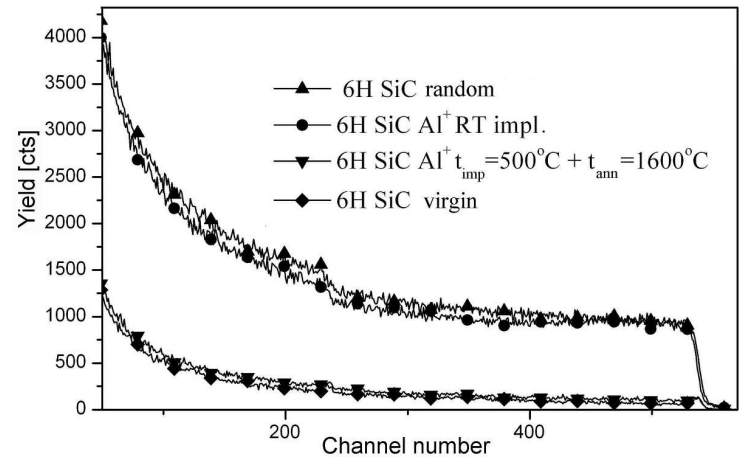

Fig. 3. RBS/C spectra of $\mathrm{Al}^{+}$implanted and $1600{ }^{\circ} \mathrm{C}$ annealed $6 \mathrm{H}-\mathrm{SiC}$ samples. Additionally, aligned and random spectra of unimplanted $6 \mathrm{H}-\mathrm{SiC}$ are shown. 
level. This is an evidence of complete amorphization of a subsurface silicon carbide layer of a few hundred nanometer thickness.

\subsection{Micro-Raman spectroscopy}

Unpolarized Raman scattering spectra measured on the unimplanted $6 \mathrm{H}-\mathrm{SiC}, \mathrm{Al}^{+}$implanted at $\mathrm{RT}$ and $500{ }^{\circ} \mathrm{C}$, and annealed at $1600^{\circ} \mathrm{C} 6 \mathrm{H}-\mathrm{SiC}$ samples are shown in Fig. 4. The first-order narrow Raman lines and much broader, two-phonon Raman modes were observed and assigned to acoustic and optic phonons of different symmetries, propagating in single-crystalline $6 \mathrm{H}-\mathrm{SiC}$. Their wave-number positions are explained by the effect of folding of the Brillouin zone that makes phonon modes away from the $\Gamma$ point present in the Raman spectra [12]. For example, the doublet structure $E_{2}$ at 767 and $790 \mathrm{~cm}^{-1}$ corresponds to the folded transverse optic (TO) modes in $6 \mathrm{H}-\mathrm{SiC}$. $\mathrm{Al}^{+}$ion implantation into $6 \mathrm{H}-\mathrm{SiC}$ at $\mathrm{RT}$ results in a serious decrease of the first-order Raman lines intensity in comparison to the virgin sample and vanishing of the two-phonon lines in the region $1500-1800 \mathrm{~cm}^{-1}$ (Fig. 4). Broad bands emerge in the Raman spectrum. These features correspond to vibrational modes of homonuclear bonds $\mathrm{Si}-\mathrm{Si}$ and $\mathrm{C}-\mathrm{C}$, as well as to vibrations typical for amorphous $\mathrm{SiC}_{x}$ compounds. Similar bands were observed previously in the Raman spectroscopic investigations of $155 \mathrm{keV} \mathrm{Na}^{+}$implanted $6 \mathrm{H}-\mathrm{SiC}[13]$ and $4 \mathrm{MeV} \mathrm{Au}^{+}$ implanted $6 \mathrm{H}-\mathrm{SiC}[14]$ and are a fingerprint of complete amorphization of implanted layers.

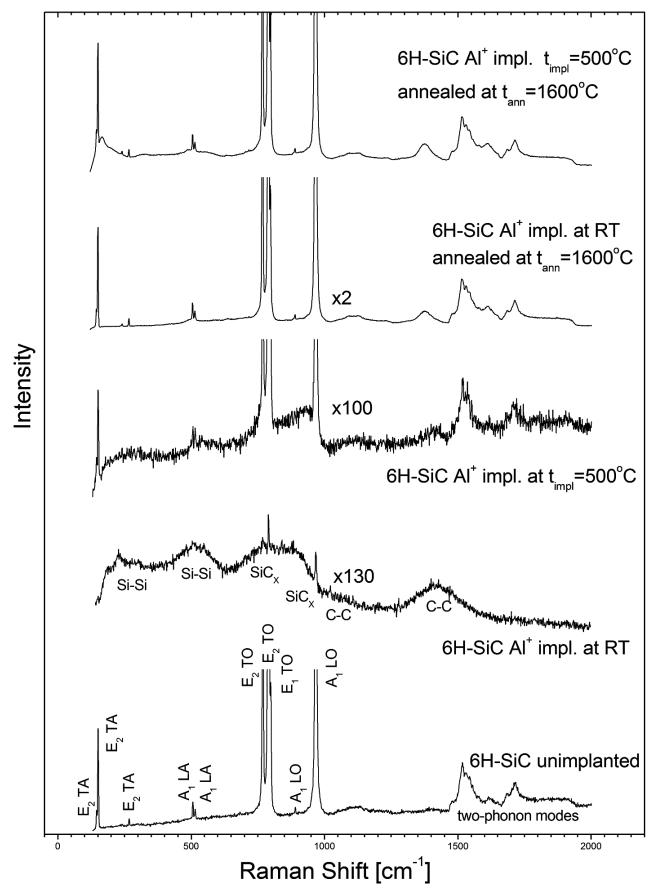

Fig. 4. Raman spectra of $\mathrm{Al}^{+}$implanted (at $\mathrm{RT}$ and $500{ }^{\circ} \mathrm{C}$ ) and $1600^{\circ} \mathrm{C}$ annealed $6 \mathrm{H}-\mathrm{SiC}$ samples.

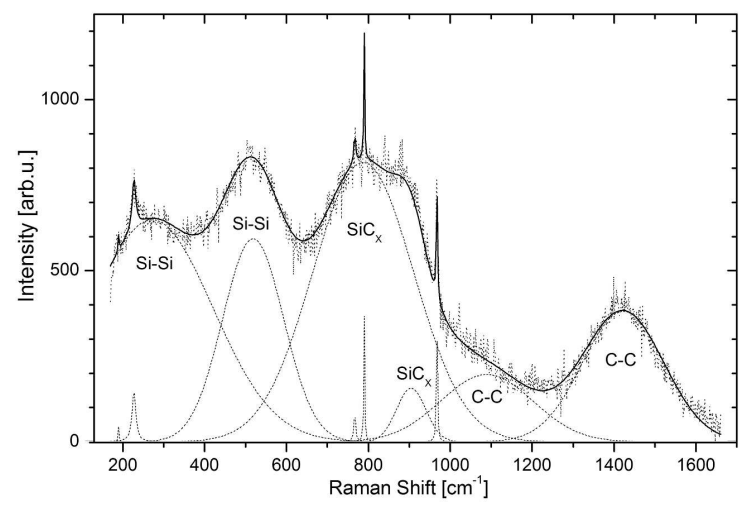

Fig. 5. Curve fit (solid line) of a full-range Raman spectrum for $\mathrm{RT} \mathrm{Al}^{+}$implanted $6 \mathrm{H}-\mathrm{SiC}$ with shown deconvoluted lines and bands (dotted line).

TABLE II

Parameters of fitted Raman lines and bands.

\begin{tabular}{c|c|c|c|c}
\hline \hline Assignment & $\begin{array}{c}\text { Lineshape } \\
\text { type }\end{array}$ & $\begin{array}{c}\text { Position } \\
{\left[\mathrm{cm}^{-1}\right]}\end{array}$ & $\begin{array}{c}\text { Height } \\
\text { [arb.u.] }\end{array}$ & $\begin{array}{c}\text { FWHM } \\
{\left[\mathrm{cm}^{-1}\right]}\end{array}$ \\
\hline cryst. Si (TA) & Lorentz & 190.1 & 56.0 & 2.2 \\
& Lorentz & 227.5 & 147.6 & 11.0 \\
Si-Si vibr. & Gauss & 271.7 & 648.7 & 349.0 \\
Si-Si vibr. & Gauss & 518.5 & 593.3 & 175.6 \\
$E_{2}$ (TO) & Lorentz & 766.7 & 82.9 & 5.8 \\
Si-C vibr. & Gauss & 787.4 & 816.4 & 290.5 \\
$E_{2}$ (TO) & Lorentz & 789.9 & 388.1 & 2.6 \\
Si-C vibr. & Gauss & 904.5 & 156.8 & 84.4 \\
$A_{1}$ (LO) & Lorentz & 967.3 & 383.2 & 2.9 \\
C-C vibr. & Gauss & 1089.2 & 196.6 & 265.2 \\
C-C vibr. & Gauss & 1422.3 & 381.5 & 233.9
\end{tabular}

The Raman spectrum for RT-implanted $6 \mathrm{H}-\mathrm{SiC}$ was fitted with a combination of Gaussian (broad bands) and Lorentzian (phonon lines) functions. Figure 5 shows the result of the best-fit calculations with components deconvoluted from the spectrum. The line-shape parameters and assignments are presented in Table II. Comparison between the above Raman spectrum and the one corresponding to $6 \mathrm{H}-\mathrm{SiC}$ sample implanted at $500{ }^{\circ} \mathrm{C}$ (Fig. 4) clearly indicates differences between both spectra. The positions of the Raman bands from the region of the $\mathrm{Si}-\mathrm{Si}$ and $\mathrm{SiC}_{x}$ modes in the $500{ }^{\circ} \mathrm{C}$ implanted sample are shifted to higher wave numbers. Additionally, the Raman lines typical for crystalline material (including two-phonon features) are observed. The ratio of integrated intensities of phonon lines and amorphous bands increases, indicating a mixture of crystalline and disordered (but not amorphous) phases in the implanted subsurface layer. The subsequent annealing for $10 \mathrm{~min}$ at $1600{ }^{\circ} \mathrm{C}$ in argon atmosphere removes the $\mathrm{Si}-\mathrm{Si}, \mathrm{C}-\mathrm{C}$ and $\mathrm{SiC}_{x}$ features from the Raman spectra and restores nar- 
row phonon lines. This observation shows a good crystalline order recovery in the implanted $6 \mathrm{H}$-SiC layers with a higher Raman scattering intensity obtained on the $500{ }^{\circ} \mathrm{C}$ implanted sample. In addition, a new feature at about $170 \mathrm{~cm}^{-1}$ of unknown origin is observed in the spectrum collected from the same sample, not present in unimplanted $6 \mathrm{H}-\mathrm{SiC}$. Also, a band at about $1400 \mathrm{~cm}^{-1}$, attributed to the $\mathrm{C}-\mathrm{C}$ bonds becomes quite strong in the Raman spectra following high temperature annealing, when compared to the virgin $6 \mathrm{H}-\mathrm{SiC}$ material. Origin of the increasing $\mathrm{C}-\mathrm{C}$ band intensity can be explained by diffusion of carbon into the surface during annealing process at such high temperature. Interestingly, this band is much weaker for the $6 \mathrm{H}-\mathrm{SiC}$ samples implanted under the same conditions but subjected to the $1500{ }^{\circ} \mathrm{C}$ annealing.

\section{Conclusion}

We have presented the results of $\mathrm{RBS} / \mathrm{C}$ and micro-Raman spectroscopy investigations of RT and $500^{\circ} \mathrm{C}$ $\mathrm{Al}^{+}$ion implantation-induced damage in $6 \mathrm{H}-\mathrm{SiC}$ and its removal by high temperature (up to $1600^{\circ} \mathrm{C}$ ) thermal annealing. The RBS/C spectra allow us to estimate the degree of radiation damage in the subsurface layers of implanted $6 \mathrm{H}-\mathrm{SiC}$ by comparison with the aligned and random backscattered $\mathrm{He}^{+}$ion yields for the unimplanted $6 \mathrm{H}-\mathrm{SiC}$. Following the $1300-1600^{\circ} \mathrm{C}$ annealing, a level of residual radiation damage in the samples implanted at RT is higher than at the $500{ }^{\circ} \mathrm{C}$ implantation. Almost complete recrystallization was confirmed in the $\mathrm{RBS} / \mathrm{C}$ spectrum of hot-implanted and annealed at $1600{ }^{\circ} \mathrm{C}$ samples.

Micro-Raman scattering measurements of $\mathrm{RT} \mathrm{Al}^{+}$implanted $6 \mathrm{H}-\mathrm{SiC}$ showed the appearance of broad bands attributed to $\mathrm{Si}-\mathrm{Si}, \mathrm{C}-\mathrm{C}$ and $\mathrm{SiC}_{x}$ vibrational modes characteristic for amorphous silicon carbide. Practically no evidence of crystalline material was present in the subsurface implanted layer. Complete deconvolution of the Raman spectrum allowed us to extract parameters of the bands and the Raman lines and propose their assignment. Micro-Raman probing also indicated that the hot-implantation of $6 \mathrm{H}-\mathrm{SiC}$ samples causes generally less damage with weaker bands characteristic for disordered but not amorphous silicon carbide. Annealing at $1600^{\circ} \mathrm{C}$ confirms recrystallization of implanted $6 \mathrm{H}-\mathrm{SiC}$ subsurface layers. The above information on damage formation and annealing as obtained by micro-Raman characterization is in a good agreement and equivalent to that from the RBS/C measurements. However, the Raman spectroscopy gives additional details on chemical reordering and formation of homonuclear bonds in damaged layers.

\section{Acknowledgments}

The authors would like to thank Prof. Z. Lisik and Dr. A. Kubiak from Technical University of Łódź for performing high temperature annealing.

This work was financially supported by the Polish Ministry of Education and Science under project PBZ-MEiN$-6 / 2 / 2006$.

\section{References}

[1] H.H. Zhang, C.H. Zhang, B.S. Li, L.H. Han, Y. Zhang, Nucl. Instrum. Methods Phys. Res. B 268, 2318 (2010).

[2] K. Kawahara, G. Alfieri, T. Kimoto, J. Appl. Phys. 106, 013719 (2009).

[3] A. Poggi, F. Moscatelli, S. Solmi, A. Armigliato, L. Belsito, R. Nipoti, J. Appl. Phys. 107, 044506 (2010).

[4] M. Gurfinkel, S. Potbhare, H.D. Xiong, J.S. Suehle, Y. Shapira, A.J. Lelis, D. Habersat, N. Goldsman, J. Appl. Phys. 105, 084511 (2009).

[5] I. Pintilie, C.M. Teodorescu, F. Moscatelli, R. Nipoti, A. Poggi, S. Solmi, L.S. Løvlie, B.G. Svensson, J. Appl. Phys. 108, 024503 (2010).

[6] V. Heera, D. Panknin, W. Skorupa, Appl. Surf. Sci. 184, 307 (2001).

[7] M. Turek, S. Prucnal, A. Drozdziel, K. Pyszniak, Rev. Sci. Instrum. 80, 043304 (2009).

[8] M. Turek, A. Drozdziel, K. Pyszniak, S. Prucnal, J. Żuk, Przeglad Elektrotechniczny 86, 193 (2010).

[9] M. Turek, S. Prucnal, A. Drozdziel, K. Pyszniak, Nucl. Instrum. Methods Phys. Res. B 269, 700 (2011).

[10] J.F. Ziegler, J.P. Biersack, M.D. Ziegler, The Stopping and Range of Ions in Matter, Lulu Press Co., Morrisville, NC, USA 2009.

[11] J. Romanek, D. Grambole, F. Herrmann, M. Voelskov, M. Posselt, W. Skorupa, J. Zuk, Nucl. Instrum. Methods Phys. Res. B 251, 148 (2006).

[12] D.W. Feldman, J.H. Parker Jr., W.J. Choyke, L. Patrick, Phys. Rev. 170, 698 (1968).

[13] W. Bolse, J. Conrad, T. Roedle, T. Weber, Surf. Coat. Technol. 74-75, 927 (1995).

[14] S. Sorieul, J.-M. Costantini, L. Gosmain, L. Thome, J.-J. Grob, J. Phys., Condens. Matter 18, 5235 (2006). 